\title{
AÇÃO DO EXTRATO PIROLENHOSO DE CASCA DE ARROZ SOBRE ASPECTOS BIOLÓGICOS E COMPORTAMENTAIS DE Spodoptera frugiperda (J. E. SMITH) (LEPIDOPTERA: NOCTUIDAE) EM MILHO
}

\author{
Cristina Jensen Vasconcelos ${ }^{1}$, Leandro do Prado Ribeiro ${ }^{1 *}$, Gilmar Vieira Coutinho ${ }^{2}$, José Djair \\ Vendramim ${ }^{1}$, Danila Helena Pinto Taba ${ }^{3}$ \\ ${ }^{1}$ Departamento de Entomologia e Acarologia, Escola Superior de Agricultura “Luiz de Queiroz"/Universidade de São Paulo \\ (ESALQ/USP), Av. Pádua Dias, 11 - Cep: 13418-900, Piracicaba, SP, lpribeiro@usp.br \\ ${ }^{2}$ Universidade Estadual de Mato Grosso do Sul (UEMS), Aquidauna, MS \\ ${ }^{3}$ Universidade Metodista de Piracicaba (UNIMEP), Piracicaba, SP
}

\section{RESUMO}

Com o intuito de buscar métodos alternativos de manejo e de elucidar a questão referente à ação inseticida do extrato pirolenhoso, realizou-se este estudo visando avaliar o efeito do extrato pirolenhoso obtido da queima da casca de arroz sobre parâmetros biológicos e comportamentais de $S$. frugiperda em milho. Foi avaliado o efeito do extrato sobre a preferência e o consumo alimentar, onde as folhas fornecidas às lagartas foram tratadas por imersão no extrato pirolenhoso a $1 \%$ (v/v), e sobre parâmetros biológicos do inseto, nesse caso, sob duas condições de aplicação: a) pulverização foliar em condições de campo (na concentração de 5\% v/v), e b) aplicação no solo em plantas mantidas em casa de vegetação, na concentração de $10 \%$ (v/v), por meio da água de irrigação. A partir dos resultados obtidos, observou-se que o extrato pirolenhoso de casca de arroz não interfere nos aspectos biológicos e comportamentais de $S$. frugiperda estudados, em nenhuma das formas de aplicação avaliadas, evidenciando sua ineficiência como método de controle desse inseto-praga.

Palavras-chave: Lagarta-do-cartucho, ácido pirolenhoso, bioatividade, Oryza sativa, Zea mays

\section{ACTION OF PYROLIGNEOUS ACID OF RICE HUSK ON BIOLOGICAL AND BEHAVIORAL ASPECTS OF Spodoptera frugiperda (J.E. SMITH) (LEPIDOPTERA: NOCTUIDAE) IN MAIZE}

\begin{abstract}
In order to seek alternative methods of management and to elucidate the question of the insecticidal activity of pyroligneous extract from burning of rice husk, this research was performed to evaluate the effect of this extract on biological and behavioral parameters of $S$. frugiperda in maize. The effect of the extract on the preference and food intake was evaluated, by providing to the larvae maize sheets immersed in pyroligneous extract at $1 \%(\mathrm{v} / \mathrm{v})$. Also, the effect on biological parameters of the insect was evaluated under two conditions: a) foliar sprays under field conditions (at the concentration of $5 \%-\mathrm{v} / \mathrm{v}$ ), and b) applied on the soil by irrigation water, in plants grown in a greenhouse at a concentration of $10 \%(\mathrm{v} / \mathrm{v})$. Considering the results obtained, it was concluded that the pyroligneous extract of rice husk does not interfere with biological and behavioral aspects of S. frugiperda, in any form of application evaluated, showing no efficiency as control method of this insect pest.
\end{abstract}

Key words: fall armyworm, pyroligneous acid, bioactivity, Oryza sativa, Zea mays 


\section{INTRODUÇÃO}

A lagarta-do-cartucho, Spodoptera frugiperda (J.E. Smith) (Lepidoptera: Noctuidae), se destaca como um dos insetospraga que mais provocam prejuízos econômicos a diversas culturas agrícolas (Prates et al. 2003), entre elas o milho, cujo rendimento dos grãos pode ser reduzido em até $54,49 \%$ devido ao ataque desse inseto (Figueiredo et al. 2006). O cultivo sucessivo de milho (safra e safrinha), principalmente na região do Cerrado, fez com que os problemas com pragas aumentassem, sobretudo com S. frugiperda (Valicente \& Cruz, 1991; Cruz, 1995). Com o consequente aumento populacional dessa praga, intensificou-se o uso de inseticidas sintéticos, propiciando assim a seleção de populações resistentes, o que tem dificultado o controle da espécie (Diez-Rodriguez \& Omoto, 2001).

Uma das alternativas para reverter esse quadro tem sido a implementação do Manejo Integrado de Pragas (MIP), que preconiza o desenvolvimento e a associação de diferentes práticas de manejo com vistas a manter a população do inseto-praga abaixo do nível de dano econômico. O uso de compostos naturais com potencial inseticida (ou insetistático) é uma prática promissora para o controle de insetos-praga (Klocke 1987), visto que não apresenta problemas de contaminação ambiental, resíduos nos alimentos, pequenos efeitos prejudiciais aos organismos benéficos (predadores e/ou parasitóides) e menor probabilidade de seleção de populações resistentes a tais compostos (Schmutterer, 1990).

Um dos compostos de origem vegetal que tem sido comercializado para o controle de insetos-praga é o extrato pirolenhoso ou ácido pirolenhoso, produto obtido pela condensação da fumaça produzida durante a carbonização da madeira (Encarnação, 2001) e que, em tese, apresenta propriedades inseticidas (Miyasaka et al. 1999), além da facilidade de obtenção e do baixo custo para o produtor.

No Brasil, há poucos estudos visando avaliar a eficiência do uso de extrato pirolenhoso no manejo fitossanitário, sendo necessárias, ainda, pesquisas com vistas a validar essa tecnologia (Souza-Silva et al., 2005). Sendo assim, desenvolveu-se este estudo com o objetivo de avaliar o efeito do extrato pirolenhoso obtido pela queima da casca do arroz (Oryza sativa) sobre aspectos biológicos e comportamentais de $S$. frugiperda em milho.

\section{MATERIAL E MÉTODOS}

Os bioensaios foram desenvolvidos no Laboratório de Plantas Inseticidas do Departamento de Entomologia e Acarologia da Escola Superior de Agricultura "Luiz de Queiroz"/Universidade de São Paulo, em Piracicaba, SP, em condições climáticas controladas (temp.: $27 \pm 2^{0} \mathrm{C}$; U.R.: $60 \pm 10 \% \mathrm{e}$ fotofase: 14 horas). Os insetos utilizados nos experimentos foram obtidos de criação mantida em dieta artificial de Burton \& Perkins (1972).

O extrato pirolenhoso da casca de arroz foi produzido no Departamento de Ciências Florestais da ESALQ/USP. Para isso, as cascas de arroz passaram por um processo de carbonização em pequenos fornos, e a fumaça proveniente desse processo foi condensada, originando o extrato pirolenhoso utilizado nos testes.

\section{Efeito na preferência e consumo alimentar}

Para este bioensaio, foram utilizadas 20 arenas (repetições), cada uma composta por uma placa de Petri de vidro de $15 \mathrm{~cm}$ de diâmetro com gesso no fundo, e recoberto com papel filtro umedecido. Folhas de milho no estádio V5 (cinco folhas expandidas) foram coletadas no campo (plantação localizada em área do campus da 
ESALQ/USP), lavadas e secas com papel toalha. A seguir, foram recortados retângulos foliares de $2 \times 4 \mathrm{~cm}\left(8 \mathrm{~cm}^{2}\right)$, no sentido longitudinal e paralelamente à nervura central. Os retângulos foliares foram imersos por 2 segundos em solução aquosa do extrato pirolenhoso a $1 \%(\mathrm{v} / \mathrm{v})$. Como testemunha foram utilizados retângulos foliares imersos em água. Antes de serem oferecidos aos insetos, os retângulos foliares foram deixados sobre papel toalha para evaporação do excesso de água. A seguir, foram colocados quatro retângulos de folhas de forma equidistante em cada arena, sendo dois deles tratados e dois não tratados (testemunha). No centro de cada arena foram liberadas 10 lagartas recém-eclodidas, sendo as placas vedadas e isoladas com filme plástico para evitar a fuga das lagartas. O número de lagartas em cada retângulo foliar foi contado 6 e 24 horas após a liberação.

Para avaliação do consumo foliar a metodologia foi a mesma utilizada no bioensaio anterior, porém no centro de cada arena foi liberada apenas uma lagarta de $4^{\circ}$ ínstar. Após 24 horas da liberação das lagartas, foi avaliada a área consumida de folhas tratadas e não tratadas em cada placa, com o auxílio de um integrador de área foliar (Li-cor Modelo LI-3000). Para este bioensaio, também se utilizaram 20 repetições.

\section{Efeito sobre aspectos biológicos de $S$. frugiperda}

Para avaliação do efeito do extrato pirolenhoso sobre alguns aspectos biológicos de $S$. frugiperda foram utilizados dois tipos de tratamento: a) via pulverização foliar e b) via aplicação no solo. Em ambos os testes, utilizaram-se 100 lagartas para cada tratamento, divididas em 10 repetições.

No experimento em que se fez pulverização foliar, as plantas de milho (híbrido G4) foram cultivadas em condições de campo, em área situada no campus da
ESALQ/USP. Ao atingirem o estádio V5, as mesmas foram submetidas a pulverizações semanais com o extrato pirolenhoso a $5 \%$ (v/v), com o auxílio de um pulverizador manual, totalizando três pulverizações durante o experimento. A partir de 24 horas após a primeira pulverização, iniciou-se $\mathrm{o}$ fornecimento das folhas tratadas às lagartas de $1^{\mathrm{o}}$ ínstar, individualizadas em tubos de vidro de $8,5 \mathrm{~cm}$ de altura e $2,5 \mathrm{~cm}$ de diâmetro. Diariamente, as folhas de milho foram coletadas no campo e fornecidas às lagartas, processo repetido até o final da fase larval. A testemunha consistiu de folhas de milho pulverizadas com água, também advindas de plantas mantidas em condições de campo.

No experimento em que foi feita aplicação no solo, as plantas do mesmo híbrido de milho foram cultivadas em casa de vegetação, em vasos com volume de solo de 1,4 litros. Os tratamentos foram iniciados quando as plantas se encontravam no estádio V5, por meio da aplicação de uma lâmina de irrigação de $23,13 \mathrm{~mm}$ do extrato pirolenhoso na concentração de $10 \%(\mathrm{v} / \mathrm{v})$. Para o controle (testemunha), aplicou-se a mesma quantidade de água. Da mesma forma que o tratamento via pulverização foliar, o fornecimento das folhas tratadas às lagartas de $1^{\circ}$ ínstar iniciou-se 24 horas após a primeira aplicação do extrato no solo, processo repetido diariamente até o final da fase larval.

Os parâmetros avaliados, nos dois casos, foram peso larval ao $5^{\circ}$ e $10^{\circ}$ dia; duração e viabilidade da fase larval; peso, duração e viabilidade da fase pupal e percentagem de adultos defeituosos.

$\mathrm{O}$ delineamento experimental adotado, em todos os bioensaios, foi $\mathrm{O}$ inteiramente aleatorizado. Para análise estatística, os dados obtidos foram testados quanto à normalidade (Teste de Shapiro Wilk) e homogeneidade das variâncias (Teste de Bartlett), realizando-se a transformação dos dados quando necessária. 
Feito isso, foram submetidos à análise de variância (ANOVA), sendo as médias comparadas pelo teste de Tukey, ao nível de $5 \%$ de probabilidade de erro.

\section{RESULTADOS E DISCUSSÃO}

\section{Efeito na preferência e consumo alimentar}

O número de lagartas recémeclodidas, nos dois períodos de avaliação (6 e 24 horas), foi maior nas folhas tratadas do que nas folhas não tratadas (testemunha) (Tabela 1), fato este que poderia conduzir, na etapa subseqüente da seleção hospedeira, a um possível efeito fagoestimulante do extrato pirolenhoso de casca de arroz. No entanto, na avaliação do consumo foliar (Tabela 1), não se observou diferença significativa entre tratamento e testemunha, o que indica que o extrato pirolenhoso, apesar de ocasionar maior atratividade de lagartas, não afeta o comportamento alimentar de $S$. frugiperda e, conseqüentemente, inviabiliza as vantagens de uma possível associação com inseticida, efeito interativo que poderia ser desejável dentro de um programa de manejo integrado, pois permitiria a redução das doses de inseticidas ao induzir a alimentação das folhas tratadas, melhorando a economicidade do sistema de manejo de $S$. frugiperda.

\section{Efeito na biologia de $S$. frugiperda}

\section{Aplicação via pulverização foliar}

Não houve diferença entre tratamento e testemunha em nenhum dos parâmetros biológicos avaliados (Tabelas 2 e 3), o que permite inferir que o extrato pirolenhoso de casca de arroz a 5\% (v/v) não interfere no desenvolvimento biológico de $S$. frugiperda, quando alimentada durante a fase larval com folhas de milho tratadas com o respectivo extrato via pulverização foliar.

\section{Aplicação sistêmica (solo)}

Os parâmetros biológicos de $S$. frugiperda, alimentada em sua fase larval com folhas de plantas de milho irrigadas com o extrato pirolenhoso de casca de arroz, diferiram significativamente da testemunha apenas na duração da fase larval, que foi menor para lagartas alimentadas com folhas de milho tratadas com o extrato pirolenhoso, e no peso larval ao $10^{\circ}$ dia, que foi maior em lagartas alimentadas com folhas tratadas (Tabelas 4 e 5). No entanto, em virtude dos poucos parâmetros afetados, que ainda contribuem para maiores níveis populacionais do inseto-praga em campo, e em detrimento da alta dose aplicada no solo, constata-se que a aplicação do extrato pirolenhoso de casca de arroz via água de irrigação não apresenta potencialidade para o manejo fitossanitário de $S$. frugiperda em milho, apesar do aspecto desejável da distribuição espacial dos resíduos advindos da queima da casca de arroz.

A ação do extrato pirolenhoso na recuperação da vitalidade das plantas e, ao mesmo tempo, na indução de resistência ao ataque de insetos mediante a ativação de substâncias do metabolismo secundário tem sido mencionada em alguns estudos (Tsuzuki et al., 2000; Azevedo et al., 2005; Campos et al., 2005; Alves, 2006). No entanto, essa ação indutora não foi observada nesta pesquisa, mesmo utilizando altas concentrações do produto (10\%).

Entretanto, segundo Alves (2006), o efeito elicitor de resistência de formulações de extrato pirolenhoso é dependente da espécie vegetal utilizada para a produção do extrato, do método de obtenção e do modo de preparo das soluções. Além disso, características físico-químicas do solo e características fisiológicas da planta e, principalmente, do inseto-praga alvo também podem interferir na resposta à aplicação de tais produtos. 
Tabela 1. Número médio de lagartas recém-eclodidas de S. frugiperda, após 6 e 24 horas da infestação, e consumo de folhas de milho tratadas e não tratadas com o extrato pirolenhoso de casca de arroz, em teste com chance de escolha. Temperatura: $27 \pm 2{ }^{\circ} \mathrm{C}$; U.R.: $60 \pm 10 \%$; fotofase: $14 \mathrm{~h}$.

\begin{tabular}{lccc}
\hline \multirow{2}{*}{ Ensaio } & \multicolumn{2}{c}{ Número médio de lagartas } & $\begin{array}{c}\text { Consumo foliar } \\
\left(\mathrm{cm}^{2}\right)\end{array}$ \\
\cline { 2 - 3 } & 6 horas & 24 horas & $3,2 \pm 0,64 \mathrm{a}$ \\
Tratadas & $2,6 \pm 0,07 \mathrm{a}$ & $2,6 \pm 0,07 \mathrm{a}$ & $4,0 \pm 0,60 \mathrm{a}$ \\
\hline
\end{tabular}

* Médias seguidas da mesma letra, nas colunas, não diferem entre si pelo teste de Tukey $(\mathrm{p} \leq 0,05)$.

Tabela 2. Peso ao $5^{\circ}$ e $10^{\circ}$ dia, duração e viabilidade da fase larval ( \pm EP) de $S$. frugiperda alimentada com folhas de milho tratadas, via pulverização foliar, com o extrato pirolenhoso de casca de arroz a $5 \%(\mathrm{v} / \mathrm{v})$. Temperatura: $27 \pm 2{ }^{\circ} \mathrm{C}$; U.R.: $60 \pm 10 \%$; fotofase: $14 \mathrm{~h}$.

\begin{tabular}{lcccc}
\hline \multirow{2}{*}{ Ensaio } & \multicolumn{2}{c}{ Peso larval $(\mathrm{mg})^{*}$} & $\begin{array}{c}\text { Viabilidade da fase } \\
\text { larval }(\%)^{* 1}\end{array}$ & $\begin{array}{c}\text { Duração da fase } \\
\text { larval (dias)* }\end{array}$ \\
\cline { 2 - 3 } & $5^{\circ}$ dia & $10^{\circ}$ dia & & \\
\hline Tratadas & $8,9 \pm 0,58$ & $158,3 \pm 8,08$ & $65,0 \pm 5,42$ & $15,2 \pm 0,13$ \\
Não tratadas & $10,9 \pm 1,87$ & $168,6 \pm 7,92$ & $76,0 \pm 6,69$ & $15,1 \pm 0,18$ \\
\hline
\end{tabular}

*Diferença não significativa pelo teste $\mathrm{F}(\mathrm{p} \leq 0,05)$;

${ }^{1}$ Para efeito estatístico, os dados foram transformados em arco-seno da raiz quadrada de x/100, porém os dados apresentados na tabela são as médias originais.

Tabela 3. Peso, duração e viabilidade da fase pupal e percentagem de adultos defeituosos ( \pm EP) de $S$. frugiperda alimentada na fase larval com folhas de milho tratadas, via pulverização foliar, com o extrato pirolenhoso de casca de arroz a $5 \%$ (v/v). Temperatura: $27 \pm 2^{\circ} \mathrm{C}$; U.R.: $60 \pm 10 \%$; fotofase: $14 \mathrm{~h}$.

\begin{tabular}{lcccc}
\hline Ensaio & $\begin{array}{c}\text { Peso de pupas } \\
(\mathrm{mg})^{*}\end{array}$ & $\begin{array}{c}\text { Duração da fase } \\
\text { pupal (dias)* }\end{array}$ & $\begin{array}{c}\text { Viabilidade da } \\
\text { fase pupal (\%)*1 }\end{array}$ & $\begin{array}{c}\text { Adultos } \\
\text { defeituosos } \\
(\%)^{* 1}\end{array}$ \\
\hline Tratadas & $176,4 \pm 2,84$ & $9,3 \pm 0,09$ & $56,0 \pm 4,52$ & $12,0 \pm 3,88$ \\
Não tratadas & $171,5 \pm 4,45$ & $9,5 \pm 0,12$ & $65,0 \pm 6,70$ & $8,0 \pm 2,90$ \\
\hline
\end{tabular}

*Diferença não significativa pelo teste $\mathrm{F}(\mathrm{p} \leq 0,05)$.

${ }^{1}$ Para efeito estatístico, os dados foram transformados em arco-seno da raiz quadrada de x/100, porém os dados apresentados na tabela são as médias originais. 
Tabela 4. Peso ao $5^{\circ}$ e $10^{\circ}$ dia, duração e viabilidade da fase larval ( \pm EP) de $S$. frugiperda alimentada com folhas de milho tratadas com o extrato pirolenhoso de casca de arroz, via aplicação sistêmica (solo). Temperatura: $27 \pm 2{ }^{\circ}$ C; U.R.: $60 \pm 10 \%$; fotofase: $14 \mathrm{~h}$.

\begin{tabular}{|c|c|c|c|c|}
\hline \multirow[t]{2}{*}{ Ensaio } & \multicolumn{2}{|c|}{ Peso larval (mg) } & \multirow{2}{*}{$\begin{array}{l}\text { Viabilidade da } \\
\text { fase }(\%)^{1}\end{array}$} & \multirow[t]{2}{*}{ Duração (dias) } \\
\hline & $5^{\circ}$ dia & $10^{\circ} \mathrm{dia}$ & & \\
\hline Tratadas & $9,6 \pm 0,27 \mathrm{a}$ & $206,8 \pm 6,48 \mathrm{a}$ & $79,0 \pm 4,06 \mathrm{a}$ & $15,1 \pm 0,11 b$ \\
\hline Não tratadas & $8,9 \pm 1,24 \mathrm{a}$ & $158,2 \pm 5,01 \mathrm{~b}$ & $74,0 \pm 4,98 \mathrm{a}$ & $15,7 \pm 0,13 \mathrm{a}$ \\
\hline
\end{tabular}

Tabela 5. Peso, duração e viabilidade da fase pupal e percentagem de adultos defeituosos ( \pm EP) de $S$. frugiperda alimentada na fase larval com folhas de milho tratadas com o extrato pirolenhoso de casca de arroz, via aplicação sistêmica (solo). Temperatura: $27 \pm 2^{\circ} \mathrm{C}$; UR: $60 \pm 10 \%$; fotofase: $14 \mathrm{~h}$.

\begin{tabular}{ccccc}
\hline Ensaio & $\begin{array}{c}\text { Peso de pupas } \\
(\mathrm{mg})^{*}\end{array}$ & \multicolumn{2}{c}{ Fase pupal } & $\begin{array}{c}\text { Adultos } \\
\text { defeituosos } \\
\end{array}$ \\
\cline { 3 - 4 } & & Duração (dias) & Viabilidade $(\%)^{1}$ & \\
\hline Tratadas & $170,7 \pm 3,04$ & $9,4 \pm 0,14$ & $72,0 \pm 5,53$ & $13,0 \pm 4,22$ \\
Não tratadas & $178,1 \pm 2,09$ & $9,5 \pm 0,06$ & $66,0 \pm 6,01$ & $6,0 \pm 1,63$ \\
\hline
\end{tabular}

\footnotetext{
*Diferença não significativa pelo teste $\mathrm{F}(\mathrm{p} \leq 0,05)$.

${ }^{1}$ Para efeito estatístico, os dados foram transformados em arco-seno da raiz quadrada de $\mathrm{x} / 100$, porém os dados apresentados na tabela são as médias originais.
}

Resultados semelhantes ao obtido nesse estudo foram observados por Pansiera et al. (2007), utilizando extrato pirolenhoso obtido de Eucalyptus grandis, Melia azedarach e Pinus caribaea, os quais constataram que o extrato pirolenhoso proveniente das três espécies arbóreas estudadas não apresenta ação inseticida ou efeito no desenvolvimento biológico (peso de larva e de pupa) de $S$. frugiperda que pudesse influenciar a sua dinâmica populacional em campo. Da mesma forma, Bogorni et al. (2008) constataram que o extrato pirolenhoso, obtido das mesmas espécies vegetais referenciadas no estudo citado anteriormente, não afeta o desenvolvimento, alimentação e oviposição da traça-do-tomateiro, Tuta absoluta (Meyrick) (Lepidoptera: Gelechiidae). Por outro lado, a aplicação de formulações comerciais de extrato pirolenhoso não ocasionou ação repelente ou de inibição nas atividades de forrageamento de Atta sexdens rubropilosa (Forel) (Hymenoptera: Formicidae) em mudas de eucalipto (SouzaSilva et al., 2005) ou efeito sobre o lepidóptero-praga da videira Argyrotaenia sphaleropa Meyrick (Lepidoptera: Tortricidae) (Morandi Filho et al., 2006). No entanto, a aplicação de Biopirol $^{\circledR}$, em proporções maiores ou iguais a 1:150 (extrato pirolenhoso: água), induziram mortalidade significativa do ácaro vetor da leprose dos citros, Brevipalpus phoenicis (Geijskes) (Acari: Tenuipalpidae) (Alves et al., 2007).

Embora, por meio deste estudo, não se verifique qualquer efeito bioativo ou 
mesmo indução de resistência a $S$. frugiperda em plantas de milho em decorrência do uso do extrato pirolenhoso, outros possíveis benefícios da aplicação desse extrato têm sido levantados em alguns estudos, como o seu efeito no fornecimento e disponibilização de nutrientes (Zanetti et al., 2004; Alves, 2006; Silva et al., 2006), seu emprego como adjuvante de caldas de pulverização (Guirado et al., 2007) ou mesmo, sua aplicabilidade no manejo de fitopatógenos de solo (Furtado et al., 2002). No entanto, estudos deverão ser realizados visando avaliar a eficiência, aplicabilidade e economicidade dessa prática no contexto geral do manejo agronômico da cultura do milho.

\section{CONCLUSÕES}

O extrato pirolenhoso de casca de arroz não tem ação sobre os aspectos biológicos e comportamentais de $S$. frugiperda estudados, em nenhuma das formas de aplicação avaliadas.

\section{REFERÊNCIAS BIBLIOGRÁFICAS}

ALVES, M.; CAZETTA, J.O.; NUNES, M.A.; OLIVEIRA, C.A.L.; COLOMBI, C.A. 2007. Ação de diferentes preparações de extrato pirolenhoso sobre Brevipalpus phoenicis (Geijskes). Revista Brasileira de Fruticultura, v.29, p.382-385.

ALVES, M. Impactos da utilização de fino de carvão e extrato pirolenhoso na agricultura. 2006. 52p. Dissertação (Mestrado em Agronomia) - Universidade Estadual Paulista "Julio de Mesquita Filho", Faculdade de Ciências Agrárias e Veterinárias, Jaboticabal, SP.

AZEVEDO, F.R.; GUIMARÃES, J.A.; SOBRINHO, R.B.; LIMA, M.A.A. 2005. Eficiência de produtos naturais para o controle de Bemisia tabaci biótipo B (Hemiptera: Aleyrodidae) em meloeiro.
Arquivos do Instituto Biológico, v.72, p.73-79.

BOGORNI, P.C.; PANSIERA, V.C.; VENDRAMIM, J.D.; RIBEIRO, L.P.; GONÇALVES-GERVÁSIO, R.C.R.; BRITO, J.O. 2008. Avaliação do efeito do ácido pirolenhoso de três espécies arbóreas sobre Tuta absoluta (Meyrick) (Lepidoptera: Gelechiidae). Bioikos, v.22, p.109-115.

BURTON, R.L.; PERKINS, W.D. 1972. WSB: a new laboratory diet for the corn earworm and the fall armyworm. Journal of Economic Entomology, v.6, p.385386.

CAMPOS, A.D.; ANTUNES, L.E.C.; FORTES, J.; RODRIGUES, A.C.; UENO, B.; COUTO, M.; OSÓRIO, V.A. 2005. Potencial do extrato de Cymbopongon citratus e extrato pirolenhoso para induzir resistência do morangueiro. In: ANAIS DO CONGRESSO NACIONAL DE HORTICULTURA, 10., Montevideo, 2005. Anais em CD... Montevideo: Sociedad Uruguaya de Hortifruticultura, 2005.

CRUZ, I. A lagarta-do-cartucho na cultura do milho. Sete Lagoas, Embrapa, 1995, 45p. (EMBRAPA-CNPMS, Circular Técnica, 21).

DIEZ-RODRIGUEZ, G.I.; OMOTO, C. 2001. Herança da resistência de Spodoptera frugiperda (J.E. Smith) (Lepidoptera: Noctuidae) a lambda-cialotrina. Neotropical Entomology, v.30, p.311316.

ENCARNAÇÃO, F. 2001. Redução do impacto ambiental na produção de carvão vegetal e obtenção do ácido pirolenhoso como alternativa para proteção de plantas. Agroecologia e Desenvolvimento Rural Sustentável, v.2, p.20-23.

FIGUEIREDO, M.L.C.; MARTINS-DIAS, A.M.P.; CRUZ, I. 2006. Relação entre a lagarta-do-cartucho e seus agentes de controle biológico natural na produção de 
milho. Pesquisa Agropecuária

Brasileira, v.4, p.1693-1698.

FURTADO, G.R.; PEREIRA, R.T.G.; ZANETTI, R.; SOUZA-SILVA, A. 2002. Efeito do ácido pirolenhoso in vitro sobre isolados de Botrytis cinerea, Cylindrocladium clavatum e Rhizoctonia solani. Fitopatologia Brasileira, v.27, p.112.

GUIRADO, N.; AMBROSANO, E.J.; ROSSI, F.; MENDES, P.C.D.; ARÉVALO, R.A. 2007. Controle alternativo da lagarta preta (Chlosine lacinia saundersii) do girassol. Revista Brasileira de Agroecologia, v.2, p.682-685.

KLOCKE, J.A. 1987. Natural plant compounds useful in insect control, p.396-415. In: WALLER, G.R. (Ed.). Allelochemicals: role in agriculture and forestry. Washington: American Chemical Society (American Chemical Society Symposium Series, 330), 1987, 606p.

MIYASAKA, S.; OHKAWARA, T.; UTSUMI, B. 1999. Controle alternativo de pragas: fumaça e carvão como valiosas armas para a agricultura orgânica. Boletim Agroecológico, v.3, p.17.

MORANDI FILHO, W.J.; BOTTON, M.; GRUTZMACHER, A.D.; GIOLO, F.P.; MANZONI, C.G. 2006. Ação de produtos naturais sobre a sobrevivência de Argyrotaenia sphaleropa (Meyrick) (Lepidoptera: Tortricidae) e seletividade de inseticidas utilizados na produção orgânica de videira sobre Trichogramma pretiosum Riley (Hymenoptera: Trichogrammatidae). Ciência Rural, v.36, n.4, p.1072-1078, 2006.

PANSIERA, V.C.; BOGORNI, P.C.; VENDRAMIM, J.D.; BRITO, J.O. 2007. Avaliação da eficiência e do modo de ação do ácido pirolenhoso obtido de três espécies arbóreas sobre Spodoptera frugiperda (J.E. Smith) (Lepidoptera: Noctuidae). Revista de Agricultura (Piracicaba), v.82, p.176-183.
PRATES, H.T.; VIANA, P.A.; WAQUIL, J.M. 2003. Atividade de extrato aquoso de folhas de nim (Azadirachta indica) sobre Spodoptera frugiperda. Pesquisa Agropecuária Brasileira, v.38, p.437439.

SCHMUTTERER, H. 1990. Properties and potential of natural pesticides from the Neem Tree, Azadirachta indica. Annual Review of Entomology, v.35, p.271-297.

SILVA, A.S.; ZANETTI, R.; CARVALHO, G.A.; MENDONÇA, L.A. 2006. Qualidade de mudas de eucalipto tratadas com extrato pirolenhoso. Revista Cerne, v.12, p.19-26.

SOUZA-SILVA, A.; ZANETTI, R.; CARVALHO, G.A.; SANTOS, A.; MATTOS, J.O.S. 2005. Preferência de formigas cortadeiras por mudas de eucalipto pulverizadas ou imersas em soluções de extrato pirolenhoso em diferentes concentrações. Scientia Florestalis, n.67, p.9-13.

TSUZUKI, E.; MORIMITSU, T.; MATSUI, T. 2000. Effect of chemical compounds in pyroligneous acid on root growth in rice plant. Japan Journal of Crop Science, v.66, p.15-16.

VALICENTE, F.H.; CRUZ, I. Controle biológico da lagarta-do-cartucho, Spodoptera frugiperda, com o baculovírus. Sete Lagoas, Embrapa, 1991, 23p. (EMBRAPA-CNPMS, Circular Técnica, 15).

ZANETTI, M.; CAZETTA, J.O.; MATTOS JÚNIOR, D.; CARVALHO, S.A. 2004. Influência do extrato pirolenhoso na calda de pulverização sobre o teor foliar de nutrientes em limoeiro. Revista Brasileira de Fruticultura, v.26, p.529533. 